\title{
sciendo
}

\section{Monitoring Changes Over a Training Macrocycle in Regional Age-Group Swimmers}

\author{
by \\ Guilherme Tucher1, Flávio Antônio de Souza Castro², Nuno Domingos Garrido², \\ Ricardo Jorge Fernandes ${ }^{4}$
}

\begin{abstract}
Our aim was to analyze physiological, kinematical and performance changes induced by swimming training in regional age-group athletes. Subjects (15.7 \pm 2.2 years old) performed a $4 \times 50$ - $m$ front-crawl test at maximal velocity (10 s rest interval) in weeks 2, 4, 9 and 12 of a 15-week macrocycle. Descriptive statistics were used and the percentage of change and smallest worthwhile change (moderate, 0.6-1.2, and large, > 1.2) were measured. Lactate concentration in the third, seventh and twelfth minute of recovery decreased significantly between weeks 2-9 (14.1, 15.7 and 17.6\%) and increased between weeks 9-12 (18.2, 18.6 and 19.8\%), with the HR presenting only trivial variations during the training period. Stroke length showed a large decrease in the first 50-m trial between weeks 4-9 (6.2\%) and a large increase between weeks 9-12 (3.1\%). The stroke rate (in all 50-m trials) increased significantly between weeks 4-9 (3$7 \%$ ) and the stroke index had a moderate to large increase in the first and third 50-m trial (3.6 and 7.1\%, respectively) between weeks 9-12. The overall time decreased by 1.1\% between weeks 2-12, being more evident after week 4 . We concluded that physiological, kinematical and performance variables were affected by the period of training in regional age-group swimmers.
\end{abstract}

Key words: macrocycle adaptations, longitudinal assessment, performance analysis, kinematics.

\section{Introduction}

Swimming performance depends on the complex relationships between technique, aerobic and anaerobic capacity, as well as psychological factors and power (Zmijewski et al. 2018). Therefore, evaluation of swimmers and training control are fundamental to better understand the interdependence between training variables (Fernandes and Vilas-Boas, 2012), allowing performance prediction and a follow-up of training process adaptations (Anderson et al., 2006; Costa et al., 2012; Lätt et al., 2010).

These data provide relevant information for coaches, swimmers and researchers, making immediate adjustments in training stimuli possible (Anderson et al., 2006; Smith et al., 2002). However, some changes in performance can occur not only as a result of inadequate training, but due to the effect of a specific training load applied in distinct periods of a given macrocycle (Barbosa et al., 2015; Costa et al., 2012, 2013). Among diverse testing protocols, the $4 \times 50$-m all-out test, proposed as a maximal lactate stimulus (Pelayo et al., 1996), is short and easy to apply in training conditions, allowing different physiological, kinematical and performance variables to be measured and compared, as well as to predict swimmers' performance.

\footnotetext{
1 - Escola de Educação Física e Desportos, Universidade Federal do Rio de Janeiro, Rio de Janeiro, Brazil. Aquatic Sports Science Research Group, GPCEA, Brazil.

2 - Aquatic Sports Research Group, Escola de Educação Física, Fisioterapia e Dança, ,Universidade Federal do Rio Grande do Sul, Porto Alegre, Rio Grande do Sul, Brazil.

3 - Research Centre in Sports Sciences, Health Sciences and Human Development, CIDESD, Vila Real, Portugal.

4 - Centre of Research, Education, Innovation and Intervention in Sport (CIFI2D), Faculty of Sports, University of Porto, Porto, Portugal; Porto Biomechanics Laboratory, LABIOMEP, University of Porto, Porto, Portugal.
} 
The relationship between swimming performance, lactate tolerance and anaerobic capacity through blood lactate concentration ([La]) assessment is a current and important topic of research (Bonifazi et al., 2000; Neiva et al., 2011; Pyne et al., 2001). Furthermore, the La utilization rate after an anaerobic test is an efficient marker of training responses. Associated to La concentration, heart rate (HR) responses are usually assessed (Anderson et al., 2008; Pelayo et al., 1996). Concomitant to the physiological assessment, technique-related variables, such as stroke length (SL), stroke rate (SR) and stroke index (SI), are regularly used to evaluate swimmers' performance (Lätt et al., 2010; Morais et al., 2012; Smith et al., 2002). In fact, more than thirty years ago, according to Costill et al. (1985), it was shown that the SL, SR and SI are all related to swimming performance, energy cost and swimming efficiency (Costill et al., 1985).

A swimming training macrocycle is frequently divided into periods with different goals and training contents (Anderson et al., 2006; Barbosa et al., 2015), and it is expected that at the end of that cycle swimmers will peak and reach their best performances (Bonifazi et al., 2000; Bosquet et al., 2007). However, different training contents during a macrocycle can induce diverse metabolic, physiological, kinematic and performance adaptations (Barbosa et al., 2015; Costa et al., 2012, 2013) which should be further studied to deepen the knowledge of the training process. In addition, the particularities of regional age-group swimmers are scarcely studied, with additional research being necessary to develop more specific, efficient and adequate training procedures (Fernandes et al., 2010; Lätt et al., 2010; Morais et al., 2012). It is also fundamental to evaluate and better understand each swimmer's individual progress and variability, besides group-mean tendencies, which is still uncommon in sports science related literature (Anderson et al., 2006).

The aim of the current study was to monitor changes over a training macrocycle in age-group swimmers, particularly by analyzing the changes of physiological (La and HR), kinematic (SL, SR and SI) and performance (swimming time/velocity) variables. It was hypothesized that these variables would be modified negatively along the middle-duration training cycle and positively at the cycle's end (coincidently with the competitive period and taper) in response to the specific stimulus of each distinct macrocycle phase. We attempted to contribute to the knowledge regarding age-group swimmers' training and performance.

\section{Methods}

\section{Participants}

Eight regional competitive swimmers, 6 boys and 2 girls, were assessed in a 15-week training macrocycle. Participants were $15.7 \pm 2.2$ years old, $170.3 \pm 7.9 \mathrm{~cm}$ in height, had $60.5 \pm 7.9$ $\mathrm{kg}$ of body mass and $4.6 \pm 0.5$ years of competitive experience. Their best performance was $32.1 \pm 2.9$ and $74.2 \pm 5.3 \mathrm{~s}(412.8 \pm 97.7$ and $363.2 \pm 98.4$ FINA point score) for the $50-\mathrm{m}$ and $100-\mathrm{m}$ freestyle, respectively. The research ethics committee of the Castelo Branco University approved the study procedure under the number 0001/2008, in accordance with the Declaration of Helsinki.

\section{Design and Procedures}

In a $25-\mathrm{m}$ swimming pool $\left(27 \pm 1^{\circ} \mathrm{C}\right.$ of water temperature), always at the same time of the day, on the first day of a weekly microcycle and after one-two days of rest, participants performed a maximal anaerobic lactate test (Pelayo et al., 1996) in the $2^{\text {nd }}, 4^{\text {th }}, 9^{\text {th }}$ and $12^{\text {th }}$ training weeks ( $\mathrm{W}_{2}, \mathrm{~W}_{4}, \mathrm{~W}_{9}$ and $\mathrm{W}_{12}$, respectively) of the August-December macrocycle. These chosen weeks represented the beginning of a training period $\left(\mathrm{W}_{2}\right)$, the end of the basic and specific period $\left(\mathrm{W}_{4}\right.$ and $\left.\mathrm{W}_{9}\right)$ and the competitive period $\left(\mathrm{W}_{12}\right)$. After a standardized 500-m warmup (200-m medley, 100-m freestyle and $4 \times 50-25$ $\mathrm{m}$ fast plus $25-\mathrm{m}$ slow front-crawl with $15 \mathrm{~s}$ rest intervals), each swimmer performed a $4 \times 50-\mathrm{m}$ front-crawl maximum velocity test (with a block start), with a $10 \mathrm{~s}$ rest interval between trials. Blood samples to determine La were collected from the index finger at the $3^{\text {rd }}, 7^{\text {th }}$ and $12^{\text {th }}$ minute (La3, La7 e La12, respectively) of recovery, using a portable analyzer (Accusport Lactimeter, Roche, Germany). To assess the La recovery dynamics, the decrease in the percentage of average $\mathrm{La}$ (\%Larec) was calculated as: (i) the La difference between minutes 3 and 7, 3 and 12, and 7 and 12 ( $\Delta$ La3-7, $\Delta$ La3-12 and $\Delta$ La7-12, respectively); (ii) the La difference referred to in the previous point divided by the time between sample collections, determining the average rate of La utilization 
( $\Delta$ La3-7/4, $\Delta$ La3-12/9 and $\Delta$ La7-12/5); and (iii) the quotients obtained in the aforementioned point, divided by the La in minute 3 ( $\Delta$ La3-7 and $\Delta$ La3-12) and $7(\Delta$ La7-12) of recovery and multiplied by 100 to obtain the rate of recovery (adapted from Pelayo et al., 1996). The heart rate (Polar FS1, China) was assessed immediately after the end of the test and the $\mathrm{HR}_{0}, \mathrm{HR}_{3}, \mathrm{HR}_{7}$ and $\mathrm{HR}_{12}$ were selected for further analysis.

Stroke length was obtained from the ratio between velocity (quotient between distance - 50$\mathrm{m}$ - and time for covering that distance) and SR (time required to perform two upper limb cycles) always on the last $25-\mathrm{m}$ split of each $50-\mathrm{m}$ trial (Chronometer Ultrak 495). For this purpose, a digital camera (Handycam Sony, Dcr Hc30, Japan), operating at $30 \mathrm{~Hz}$, was placed at the $5^{\text {th }}$ and $6^{\text {th }} \mathrm{m}$ from the lateral and turning walls, respectively. The stroke index (SI) was obtained by multiplying swimming velocity and $\mathrm{SL}(\mathrm{SI}=\mathrm{v}$ * SL; Costill et al., 1985). Time was always measured after each repetition by the same experienced coach and the overall time was obtained by adding the time of the four repetitions, allowing the assessment of each 50-m velocity ( v1, V2, v3 and v4) and overall velocities (Voverall).

\section{Training Program}

Within the 15-week training program, swimmers completed all the pre-established training sessions (one per day with a volume of $15.0 \pm 6.2 \mathrm{~km} /$ week) and were instructed as to the importance of adequate nutrition and hydration. The training macrocycle was divided into: (i) a basic preparatory period (weeks 1 to 3 ), aiming to develop aerobic capacity and power; (ii) a specific preparatory period (weeks 4 to 9), with the purpose to develop anaerobic capacity and power and maintain the aerobic condition; (iii) a competitive period (weeks 10 to 14), aiming to peak by recovering from previous training loads, guaranteeing the optimization of acquired physical and technical conditions; and (iv) a transition period (week 15), seeking a physical and psychological break between heavy training loads.

Five levels of intensity were used to characterize the swimming training sessions (adapted from Mujika et al., 1995): (i) aerobic capacity 1, using low-intensity continuous exercises; (ii) aerobic capacity 2, with exercises performed at the anaerobic threshold intensity; (iii) aerobic power, using exercises aiming to develop maximal oxygen uptake; (iv) anaerobic lactic, including exercises leading to lactate production and tolerance; and (v) anaerobic alactic, implementing exercises that did not depend on glycolysis, but mainly on phosphocreatine. Average swimming distance and different percentages of the total swimming distance covered for each intensity throughout the macrocycle training periods are displayed in Table 1.

\section{Statistical Analysis}

Data were presented as average \pm standard deviation (SD). Smallest worthwhile changes were used to calculate if the magnitude (training) effect was, according to Hopkins (2002), beneficial, trivial or harmful, representing the change required to indicate performance improvement (Barnes and Kilding, 2015).

It was assumed that the lower value in the smallest worthwhile change, which could have a direct relation to performance, was $0.2 \times \mathrm{SD}$ among the subjects (Boyd et al., 2011; Impellizzeri et al., 2008) and it was presented as a percentage, allowing comparison with the literature. Qualitative values indicating the possibility of a substantial increase or decrease were: (i) $<1 \%$, almost certainly not; (ii) $<5 \%$, very improbable; (iii) $<25 \%$, improbable or probably not; (iv) $<50 \%$, possibly not; (v) $>50 \%$, possible; (vi) $>75 \%$, probable; (vii) $>95 \%$, very probable; and (viii) $>$ $99 \%$, almost certain (Liow and Hopkins, 2003). When the change of effect was probable, the effect size was also presented (as mean $\pm 95 \%$ of the confidence limits) and the difference interpreted as: (i) trivial, < 0.2 ; (ii) small, 0.2-0.6; (iii) moderate, $0.6-1.2$; and (iv) large, $>1.2$ (Anderson et al., 2006; Saunders et al., 2004).

\section{Results}

Physiological, kinematical and performance related variables obtained in the beginning of the basic training period (week 2), beginning and end of the specific preparatory period (weeks 4 and 9) and during the competitive period (week 12) of the training macrocycle are displayed in Table 2.

La3 decreased by 15.0 and $14.1 \%$ between weeks 2-4 and 2-9, respectively, and increased by 18.2\% between weeks 9-12. La7 decreased by 17.1 
and $15.7 \%$ between weeks 2-4 and 2-9, respectively, but rose by 20.5 and $18.6 \%$ between weeks 4-12 and 9-12, respectively. La12 decreased by $9.1,17.6$ and $9.3 \%$ between weeks 2-4, 2-9 and 4-9, respectively, with a later increase of $19.8 \%$ between weeks 9-12. Swimmers' individual variations for $\mathrm{La}_{3}, \mathrm{La} 7$ and La12 were \pm 16.3 , 17.0 and $17.1 \%$, respectively. \%Larec3-12 increased by $63.4 \%$ between weeks 4-12 and \%Larec7-12 decreased by $96.9 \%$ between weeks $2-4$, and increased by more than $100 \%$ later, between weeks 4-12. Only trivial alterations in the HR were observed among the tests carried out, with swimmers' individual variations for $\mathrm{HR}_{0}, \mathrm{HR}_{3}$, $\mathrm{HR}_{7}$ and $\mathrm{HR}_{12}$ being $\pm 8.7,8.9,7.6$ and $6.2 \%$, respectively.

SL1 decreased by 3.0 and $6.2 \%$ between weeks 2-9 and 4-9, respectively, and increased by $3.1 \%$ between weeks 9-12 (SL2 also decreased by $2.8 \%$ between weeks 4-9). SL3 decreased by 3.7 and $2.0 \%$ between weeks 2-9 and 4-9, respectively, and L4 decreased by 3.6, 2.7 and $4.6 \%$ between weeks 2-12, 4-9 and 4-12, respectively. Swimmers' individual response varied by $\pm 6.1,4.1,6.5$ and $5.0 \%$ for $\mathrm{SL}_{1}, \mathrm{SL}_{2}, \mathrm{SL}_{3}$ and $\mathrm{SL}_{4}$, respectively. $\mathrm{SR}_{1}$ presented a decrease of 6.7 and $2.8 \%$ between weeks 2-4 and 2-12, respectively, but an increase of $7.1 \%$ was observed between weeks $4-9$. SR2 and $\mathrm{SR}_{3}$ rose by 3.1 and $3.4 \%$ vs. 4.6 and $4.8 \%$ between weeks 2-9 and 4-9, respectively. SR 4 presented a $4.8,5.9,4.2$ and 5.3\% increase between weeks 2-9, 2-12, 4-9 and 4-12, respectively. Swimmers individual response varied by $\pm 7.4,5.2,5.3$ and $5.2 \%$ for $\mathrm{SR}_{1}, \mathrm{SR}_{2} \mathrm{SR}_{3}$ and $\mathrm{SR}_{4}$. $\mathrm{SI}_{1}$ initially decreased by 5.8 and $4.2 \%$ between weeks $2-9$ and 4-9, respectively, but increased by $3.6 \%$ between weeks 9-12. $\mathrm{SI}_{3}$ presented a 4.8 and $7.1 \%$ increase between weeks 2-12 and 9-12 (SI 2 and $\mathrm{SI}_{4}$ - only trivial alterations). Swimmers' individual response varied by $\pm 5.2,4.5,8.9$ and $7.0 \%$ for $\mathrm{SI}_{1}$, $\mathrm{SI}_{2}, \mathrm{SI}_{3}$ and $\mathrm{SI}_{4}$, respectively. The overall velocity had an increase of $1.2 \%\left(0.02 \pm 0.04 \mathrm{~m} \cdot \mathrm{s}^{-1}\right), 1.4 \%$ $\left(0.02 \pm 0.03 \mathrm{~m} \cdot \mathrm{s}^{-1}\right)$ and $1.9 \%\left(0.03 \pm 0.05 \mathrm{~m} \cdot \mathrm{s}^{-1}\right)$ between weeks 2-12, 4-9 and 4-12, respectively, with swimmers' individual performance varying by $\pm 2.0 \%$ in the overall velocity. Table 3 displays data of the relevant training effects during the testing weeks.

Table 1

Average absolute and relative volume (per each intensity area) throughout the different periods of the training macrocycle

\begin{tabular}{|c|c|c|c|c|c|c|}
\hline $\begin{array}{l}\text { Training } \\
\text { period }\end{array}$ & $\begin{array}{l}\text { Volume } \\
(\mathrm{km})\end{array}$ & $\begin{array}{c}\text { Aerobic } \\
\text { capacity } 1 \\
(\%)\end{array}$ & $\begin{array}{c}\text { Aerobic } \\
\text { capacity } 2 \\
(\%)\end{array}$ & $\begin{array}{c}\text { Aerobic } \\
\text { power (\%) }\end{array}$ & $\begin{array}{l}\text { Anaerobic } \\
\text { lactic (\%) }\end{array}$ & $\begin{array}{l}\text { Anaerobic } \\
\text { alactic (\%) }\end{array}$ \\
\hline Basic & 19.2 & 75.5 & 11.2 & 11.2 & 1.5 & 0.4 \\
\hline Specific & 19.5 & 71.0 & 10.4 & 12.3 & 3.4 & 0.7 \\
\hline Competitive & 11.9 & 71.2 & 10.4 & 10.2 & 4.4 & 1.1 \\
\hline Transition & 7.4 & 97.3 & 0 & 0 & 1.4 & 1.4 \\
\hline
\end{tabular}


Table 2

Mean $\pm S D$ values of blood lactate concentration (La), decrease in lactate concentration $(\%$ Larec), heart rate (HR), stroke length $(S L)$, stroke rate (SR), stroke index (SI), velocity at each 50-m repetition and its overall mean (v) along weeks 2, 4, 9 and 12 of the swimming training macrocycle

\begin{tabular}{lllll}
\hline Variables & Week 2 & Week 4 & Week 9 & Week 12
\end{tabular}

\begin{tabular}{lllll}
\hline $\mathrm{La} 3\left(\mathrm{~mm} \cdot \mathrm{l}^{-1}\right)$ & $13.0 \pm 0.8$ & $11.0 \pm 2.1$ & $11.1 \pm 2.8$ & $13.2 \pm 3.1$
\end{tabular}

$\operatorname{La} 7\left(\mathrm{~mm} \cdot \mathrm{l}^{-1}\right)$

$\operatorname{La} 12\left(\mathrm{~mm} \cdot \mathrm{l}^{-1}\right)$

$\%$ Larec3-7 $\left(\% \cdot \min ^{-1}\right)$

\%Larec3-12 $\left(\% \cdot \min ^{-1}\right)$

$\%$ Larec7-12 $\left(\% \cdot \mathrm{min}^{-1}\right)$

$\mathrm{HR}_{0}(\mathrm{bpm})$

$\mathrm{HR}_{3}(\mathrm{bpm})$

$\mathrm{HR}_{7}$ (bpm)

$\mathrm{HR}_{12}$ (bpm)

$\mathrm{SL}_{1}\left(\mathrm{~m} \cdot \mathrm{cycle}^{-1}\right)$

$\mathrm{SL}_{2}\left(\mathrm{~m} \cdot \mathrm{cycle}^{-1}\right)$

$\mathrm{SL}_{3}\left(\mathrm{~m} \mathrm{cycle}^{-1}\right)$

$\mathrm{SL}_{4}\left(\mathrm{~m}^{\mathrm{cycle}}{ }^{-1}\right)$

$\mathrm{SR}_{1}\left(\right.$ cycle $\left.\mathrm{min}^{-1}\right)$

$\mathrm{SR}_{2}\left(\right.$ cycle $\mathrm{min}^{-1}$ )

$\mathrm{SR}_{3}\left(\right.$ cycle $\left.\cdot \mathrm{min}^{-1}\right)$

$\mathrm{SR}_{4}\left(\right.$ cycle $\left.\mathrm{min}^{-1}\right)$

$\mathrm{SI}_{1}$
$\mathrm{SI}_{2}$
$\mathrm{SI}_{3}$
$\mathrm{SI}_{4}$
$\mathrm{~V} 1\left(\mathrm{~m} \cdot \mathrm{s}^{-1}\right)$
$\mathrm{V} 2\left(\mathrm{~m} \cdot \mathrm{s}^{-1}\right)$
$\mathrm{V} 3\left(\mathrm{~m} \cdot \mathrm{s}^{-1}\right)$
$\mathrm{V} 4\left(\mathrm{~m} \cdot \mathrm{s}^{-1}\right)$

Voverall $\left(\mathrm{m} \cdot \mathrm{s}^{-1}\right)$
$11.8 \pm 0.7$

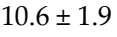

$2.1 \pm 1.0$

$2.0 \pm 1.4$

$2.1 \pm 2.9$

$174.8 \pm 11.3$

$125.6 \pm 9.6$

$111.6 \pm 10.4$

$114.0 \pm 10.9$

$1.97 \pm 0.18$

$1.95 \pm 0.19$

$1.92 \pm 0.23$

$1.90 \pm 0.21$

$48.01 \pm 4.42$

$41.50 \pm 3.59$

$39.16 \pm 3.61$

$38.74 \pm 3.75$

$$
\begin{aligned}
& 3.12 \pm 0.41 \\
& 2.64 \pm 0.32 \\
& 2.40 \pm 0.39 \\
& 2.33 \pm 0.34 \\
& 1.57 \pm 0.11 \\
& 1.34 \pm 0.05 \\
& 1.24 \pm 0.07 \\
& 1.22 \pm 0.06
\end{aligned}
$$

$1.33 \pm 0.06$
$38.94 \pm 3.06$

$40.61 \pm 2.08$

$41.04 \pm 2.17$

$8.7 \pm 2.3$

$2.2 \pm 3.2$

$10.4 \pm 3.2$

$2.7 \pm 4.0$

$2.3 \pm 1.6$

$5 \pm 2.2$

$2.4 \pm 0.8$

$2.3 \pm 2.4$

$0.06 \pm 3.7$

$161.3 \pm 16.8$

$113.1 \pm 10.7$

$113.0 \pm 11.8$

$109.1 \pm 20.0$

$104.0 \pm 11.2$

$105.5 \pm 8.2$

$105.1 \pm 9.9$

$2.04 \pm 0.26$

$1.91+0.12$

$1.97 \pm 0.11$

$1.96 \pm 0.20$

$1.91 \pm 0.18$

$1.91 \pm 0.23$

$1.93 \pm 0.28$

$1.92 \pm 0.19$

$1.94 \pm 0.20$

$1.83 \pm 0.20$

$44.77 \pm 6.99$

$47.99 \pm 3.50$

$41.40 \pm 4.23$

$42.81 \pm 4.04$

$40.98 \pm 2.49$

$46.66 \pm 2.58$

$42.89 \pm 5.38$

$40.03 \pm 3.04$

$39.08 \pm 4.21$

$$
\begin{aligned}
& 3.07 \pm 0.42 \\
& 2.65 \pm 0.34 \\
& 2.41 \pm 0.48 \\
& 2.40 \pm 0.30 \\
& 1.50 \pm 0.11 \\
& 1.34 \pm 0.06 \\
& 1.24 \pm 0.09 \\
& 1.24 \pm 0.04
\end{aligned}
$$

$2.94 \pm 0.32$

$3.04 \pm 0.33$

$2.59 \pm 0.29$

$2.60 \pm 0.39$

$2.35 \pm 0.46$

$2.52 \pm 0.37$

$2.38 \pm 0.32$

$2.32 \pm 0.47$

$1.53 \pm 0.09$

$1.53 \pm 0.10$

$1.35 \pm 0.07$

$1.35 \pm 0.08$

$1.25 \pm 0.11$

$1.29 \pm 0.07$

$1.26 \pm 0.08$

$1.25 \pm 0.12$

$1.32 \pm 0.05 \quad 1.34 \pm 0.07 \quad 1.35 \pm 0.08$




\begin{tabular}{|c|c|c|c|c|c|c|}
\hline \multicolumn{7}{|c|}{$\begin{array}{l}\text { Table } 3 \\
\text { Effect size (mean } \pm 95 \% \text { confidence limit) for blood lactate concentration (La), } \\
\text { percentage of average decrease in the lactate concentration (\%Larec), stroke length (SL), } \\
\text { stroke rate }(S R) \text {, stroke index }(S I), 50 \text { - } m \text { velocity from the first, second and fourth } 50-m \\
\text { repetitions }\left(v_{1}, v_{3} \text { and } v_{4}\right) \text { and overall velocities }\left(v_{\text {overall }}\right) \text { found between the testing weeks } \\
2,4,9 \text { and } 12(\mathrm{~W})\end{array}$} \\
\hline Variables & $\mathbf{W}_{2}-\mathbf{W}_{4}$ & $\mathbf{W}_{2}-\mathbf{W}_{9}$ & $W_{2}-W_{12}$ & $\mathbf{W}_{4}-W_{9}$ & $W_{4-} W_{12}$ & $W_{9-} W_{12}$ \\
\hline $\mathrm{La}_{3}$ & $2.6 \pm 2.2 \%$ & $2.0 \pm 2.3 \%$ & - & - & - & $3.0 \pm 2.3 \%$ \\
\hline $\mathrm{La} 7$ & $2.5 \pm 2.2 \%$ & $2.5 \pm 2.2 \%$ & - & - & $2.2 \pm 2.3 \%$ & $3.4 \pm 2.3 \%$ \\
\hline $\mathrm{La}_{12}$ & $1.6 \pm 2.4 \%$ & $2.2 \pm 2.3 \%$ & - & $1.6 \pm 2.3 \%$ & - & $1.8 \pm 2.3 \%$ \\
\hline$\%$ Larec3-12 & - & - & - & - & $2.9 \pm 2.3 \%$ & - \\
\hline$\%$ Larec7-12 & $2.0 \pm 2.3 \%$ & - & - & - & $1.6 \pm 2.3 \%$ & - \\
\hline $\mathrm{SL}_{1}$ & - & $1.1 \pm 1.8 \%$ & - & $1.5 \pm 2.3 \%$ & - & $1.3 \pm 2.2 \%$ \\
\hline $\mathrm{SL}_{2}$ & - & - & - & $1.6 \pm 2.3 \%$ & - & - \\
\hline $\mathrm{SL}_{3}$ & - & $1.4 \pm 2.3 \%$ & - & $1.5 \pm 2.3 \%$ & - & - \\
\hline $\mathrm{SL}_{4}$ & - & - & $1.2 \pm 2.0 \%$ & $1.4 \pm 2.2 \%$ & $1.3 \pm 2.2 \%$ & - \\
\hline $\mathrm{SR}_{1}$ & $1.3 \pm 2.2 \%$ & - & $1.1 \pm 1.8 \%$ & $1.5 \pm 2.3 \%$ & - & - \\
\hline $\mathrm{SR}_{2}$ & - & $1.7 \pm 2.1 \%$ & - & $1.6 \pm 2.3 \%$ & - & - \\
\hline $\mathrm{SR}_{3}$ & - & $3.2 \pm 2.1 \%$ & - & $1.9 \pm 2.2 \%$ & - & - \\
\hline $\mathrm{SR}_{4}$ & - & $1.5 \pm 1.9 \%$ & $2.1 \pm 2.3 \%$ & $1.6 \pm 2.0 \%$ & $1.9 \pm 2.3 \%$ & - \\
\hline SI 1 & - & $2.4 \pm 2.3 \%$ & - & $1.3 \pm 2.2 \%$ & - & $1.4 \pm 2.3 \%$ \\
\hline $\mathrm{SI}_{3}$ & - & - & $1.3 \pm 2.2 \%$ & - & - & $1.1 \pm 1.8 \%$ \\
\hline $\mathrm{v} 1$ & $2.4 \pm 2.3 \%$ & $2.8 \pm 2.2 \%$ & $1.9 \pm 2.3 \%$ & $1.7 \pm 2.3 \%$ & $1.6 \pm 2.3 \%$ & - \\
\hline v3 & - & - & $2.6 \pm 2.2 \%$ & - & $1.7 \pm 2.3 \%$ & $1.1 \pm 2.3 \%$ \\
\hline $\mathrm{V}_{4}$ & $1.6 \pm 2.3 \%$ & $2.0 \pm 2.3 \%$ & $1.1 \pm 2.3 \%$ & $1.2 \pm 2.3 \%$ & - & - \\
\hline Voverall & - & - & $1.2 \pm 2.3 \%$ & $1.5 \pm 2.3 \%$ & $1.5 \pm 2.3 \%$ & - \\
\hline & Note: e & $\begin{array}{l}\text { size refers } \\
\text { ffect: moder }\end{array}$ & $\begin{array}{l}\text { ly to varial } \\
0.6-1.2 ; a\end{array}$ & $\begin{array}{l}\text { with benef } \\
\text { large, }>1.2\end{array}$ & al effect & \\
\hline
\end{tabular}

\section{Discussion}

In the current study, regional age-group swimmers performed a maximum anaerobic test to assess training induced physiological, kinematic and performance changes, with swimmers' individual response magnitude being also estimated. This type of evaluation and training control of swimmers is rarely implemented since follow-up studies are difficult, especially if a biophysical approach (a combination of physiological and biomechanical analysis) is adopted. The goal of competitive swimming is to cover the race distance as fast as possible, depending on swimmers' ability to maximize propulsion, which is conditioned by both their technique and capacity to supply energy (Figueiredo et al., 2013). Given this, the use 
of a biophysical evaluation is well justified. In addition, in the present study, swimming performance was also evaluated and, even if not during a formal competition, considering La concentration and the shorter time duration of the anaerobic test, it seems that an adequate physiological environment for performance improvement was created (Bonifazi et al., 2000).

Since inferential tests offer limited interpretation of performance changes (Atkinson, 2003; Hopkins, 2002), a magnitude quantification effect analysis by means of probability criteria was implemented in the current study. However, no studies assessing individual responses of agegroup swimmers during a training program can be found in the available literature, limiting data comparison. The individual and average changes over a training macrocycle were observed in regional age-group swimmers, which could be useful for coaches, although the sample size and participants' competitive level should be taken into consideration, as well as the fact that different factors can contribute to these alterations (Morais et al., 2014). It is important to highlight that training was similar for all participants, respecting swimmer's characteristics and particularities.

The wide La3 intra-subjects variability obtained between testing weeks $(\sim 16.3 \%)$ may be explained by the different training stimulus along the macrocycle (Bonifazi et al., 2000). The obtained La3 and La12 values were lower than those previously found, yet similar La12 values were observed at the end of the basic preparatory period (Pelayo et al., 1996). These differences in results may be due to the use of younger and less experienced swimmers (Pelayo et al., 1996), although our data are in agreement with the results of Neiva et al. (2011) with older swimmers. In the period of aerobic training of greatest intensity (weeks 2-4), there was a decrease of $\sim 96 \%$ in \%Larec7-12, different from what was observed in the literature (Pelayo et al., 1996). Yet, with increasing anaerobic conditioning (weeks 412 ), an increase of $\sim 63$ and $>100 \%$ in the \%Larec312 and \%Larec7-12, respectively, was observed and in the competitive period a greater \%Larec312 was found than that reported before $(1.5 \pm 0.8$ $\% \cdot$ min-1) by Pelayo et al. (1996).

These results showed that a high volume of low-intensity aerobic training concurrently with a low percentage of intense aerobic and anaerobic stimuli during the basic preparatory period (weeks 1-3) brought negative changes in week $4 \mathrm{La}$ concentration, even if it did not apparently lead to a relevant decrease in the anaerobic test results (Pelayo et al., 1996). In fact, in week 4 there was a decrease of La3 and \%Larec7-12, indicating an anaerobic condition deterioration and decreased La utilization capacity both of which are considered undesirable effects of training (Bonifazi et al., 2000; Deminice et al., 2007). Therefore, even if these variables are positively adjusted in the following weeks, the relevance of using a high percentage of low intensity aerobic training (and low anaerobic conditioning) in the first three training weeks is questionable. However, it is worth saying that technical development is of paramount importance and is usually conducted at low intensity paces (Fernandes et al., 2010; Lätt et al., 2010; Morais et al., 2012). In addition, even for elite athletes whose specialty are events of high intensity (between 1 and $8 \mathrm{~min}$ ), it is suggested that $\sim 75 \%$ of total training volume should be performed at low intensities (Laursen, 2010). In any case, the use of intensive training is reported to bring positive effects to both the capacity to perform maximal and submaximal exercises, as well as to La utilization (Bishop et al., 2011; Laursen, 2010; Serpiello et al., 2011).

Regarding HR values, those identified after our tests were lower than those reported in 17 male swimmers and after swimming incremental and maximal tests (200 and $400 \mathrm{~m}$ ): 179 vs. $183 \mathrm{bpm}$ (Suk et al., 2016). Using the smallest worthwhile change procedures, with $2.3 \%$ as the typical error of reference (Anderson et al., 2006), only trivial changes were noticed during the training program, despite the observed swimming performance variations. Thus, regardless of performance differences, this fact may indicate that swimmers gave their best during testing or, at least, they swam in similar effort conditions (Anderson et al., 2006). It has also been reported that the peak HR is a physiological variable that remains stable within the first three training years, decreasing then in the following years in male swimmers, while in female swimmers a decrease of $\sim 1.1 \%$ per year is observed (Anderson et al., 2006).

The current SL and SR results ranged from $1.8-2.0 \mathrm{~m} \cdot$ cycle-1 to $38.7-48.0$ cycles.min-1, 
respectively, while previous studies using swimmers of similar age and training level observed: (i) higher SL $(2.6 \pm 0.2 \mathrm{~m} \cdot$ cycle- 1$)$ and a lower SR $(35.8 \pm 1.1$ cycles-min- 1$)$ for the first 100 $\mathrm{m}$ bout of a $6 \times 100-\mathrm{m}$ front crawl, with both variables decreasing in the following $100-\mathrm{m}$ repetitions (Deminice et al., 2007) and (ii) shorter SL (1.5 $\pm 0.2 \mathrm{~m} \cdot$ cycle- 1$)$ and a higher SR (values were not presented) for a shorter maximal $25-\mathrm{m}$ test (Morais et al., 2012). These differences may be due to the characteristics of the stimuli used, the methodology applied and swimmers' anthropometric characteristics (Craig and Pendergast, 1979; Morais et al., 2012). Additionally, in accordance with a previous study (Anderson et al., 2006), a SL decline and a SR increase from the beginning to the middle of the macrocycle were observed. However, with the posterior increase of anaerobic workouts, the SR increased (until week 9) as well as the SI1 (weeks 9-12) and the SI3 (weeks 2-12 and 9-12), evidencing a technical quality improvement (Morais et al., 2012). In fact, the SI improved both when the swimmer was rested (SI1), knowing how to technically take advantage of this condition, and at the end of the stimulus (SI3), when fatigue was considered at its highest level.

The augmented velocity values from weeks 4-9 and 4-12 were higher than those from weeks $2-12(1.2 \%)$ and are in line with the progression found: (i) in the middle of the training and tapering periods for women (1.6 and $1.5 \%, \mathrm{CL} \pm 1.2$ and $1.0 \%$, respectively) and at the middle training phase for men $(1.4 \%, \mathrm{CL} \pm 1.1 \%)$ (Anderson et al., 2006); and (ii) after the tapering period (Bonifazi et al., 2000; Olbrecht, 2000; Pyne et al., 2001, 2009). Therefore, within the macrocycle, a "detraining" period characterized by a high proportion of general and low intensity activities and exercises (Anderson et al., 2008; Bishop et al., 2008) seems to exist. Moreover, the traditional volume reduction that occurs during the taper leads to subsequent improved performance (Bosquet et al., 2007; Mujika and Padilla, 2000; Pyne et al., 2009), with an improvement of $\sim 1.5-3 \%$ expected after that training period (Pyne et al., 2009). Despite the current study short macrocycle duration, the obtained similar percentage of the performance increase can be explained by a lower swimming proficiency level of the participants, indicating greater physiological adaptability to training stimuli (Bonifazi et al., 2000).

Poor swimmers' performance at the start of each macrocycle can be due to a previous transition period (Anderson et al., 2006), evidencing a cyclic sport performance (Mujika and Padilla, 2000; Olbrecht, 2000). In the current study, lack of a prior transition period justifies the similitude between the behavior of the variables between week 2 and weeks 9 and 12. In fact, it had been observed before that the absence of a transitional/detraining period between two training macrocycles allowed the maintenance of the performance level at the beginning of the subsequent training period (Mujika and Padilla, 2000). Moreover, age-group swimmers naturally improve some biomechanical related variables due to their growth process (Moreira et al., 2014), revealing the importance of defining which is the best strategy to promote progression of age-group swimmers performance.

A limitation of the current study is that no test-retest reliability assessment was carried out to obtain the measurement error, which is common in this type of statistical procedure (Hopkins, 2000); nevertheless data were compared with reference values available in literature (Anderson et al., 2006). In addition, SL, SR and SI were measured manually, simplifying the procedure and facilitating its use by coaches (Anderson et al., 2006; Morais et al., 2012), although more sophisticated methodologies could be used to improve the process of obtaining the data (Smith et al., 2002). Another possible limitation of the current study was the lack of determination of the swimmers' biological age, as the relationship between growth factors and training in sports performance is well recognized (Barbosa et al., 2015; Moreira et al., 2014). However, the absence of a relationship between sexual maturation and 100-m front-crawl performance had been previously observed (Lätt et al., 2010), showing the major importance of a training process in performance. Finally, the heterogeneity of the sample may have influenced the obtained data, despite being in accordance with literature (Anderson et al., 2006; Barbosa et al., 2015; Morais et al., 2014).

Several practical implications may be drawn from this study, particularly the fact that the $4 \times 50$-m front-crawl test can provide coaches 
with an easy means to control technique, aerobicanaerobic conditioning and performance along the training process using just one test. The HR, however, does not appear to be affected by the training period. However, as the $4 \times 50$-m test is a maximal intensity test, motivational factors can decisively influence final performance, which should be a concern for coaches (Smith et al., 2002). Thus, testing should be part of the annual activity plan and carefully scheduled within specific macrocycle periods in order to avoid data misinterpretation (Barbosa et al., 2015; Olbrecht, 2000).

\section{Conclusion}

The behavior of physiological (La), kinematic (SL, SR and SI) and performance (swimming velocity) related variables is dependent on the specific training content of each macrocycle period, with the respective changes explained by the importance of each motor ability and by the effects of the recovery periods. Each swimmer seems to demonstrate an individual way of responding to training and presents individual variations. The most remarkable effect size values (> 3\%) occurred for $\mathrm{La} 3$ and $\mathrm{La} 7$ in weeks 9-12, and for SR3 in weeks 2-9, but the HR was not sensible to changes with different training loads. Better performance conditions are present at the middle and the end of the macrocycle due to greater anaerobic stimuli offered and benefits of the tapering period. Some changes in variables observed in test performance during the different periods of training can be considered negative to specific performance. However, swimming coaches should keep in mind that this can be a natural process to improve performance in the long term and it is dependent on the training period. Thus, the result obtained in the test should be evaluated with caution and the individual characteristics of the swimmer and the training phase in which the test was performed during the season should be taken into account. Moreover, as discussed earlier, the training stimuli offered in one phase will induce physiological and mechanical adaptations consistent with this type of a stimulus. Thus, the test results should take this variable into account. Considering all of these variables when analyzing test results will allow to better understand whether adaptations to training will lead to adequate performance in the future, or whether adaptations are actually inconsistent with what is expected for this macrocycle phase.

\section{Acknowledgements}

To the Federal Institute of Education, Science and Technology of the Southeast of Minas Gerais for the financial support.

To Dr. Orquídia Ribeiro from the Department of Letters, Arts \& Communication of the University of Trás-os-Montes \& Alto Douro, for revising the text.

To NanoSTIMA: Macro-to-Nano Human Sensing: Towards Integrated Multimodal Health Monitoring and Analytics (NORTE-01-0145-FEDER-000016), co-financed by the Fundo Europeu de Desenvolvimento Regional (FEDER) through NORTE 2020.

\section{References}

Anderson ME, Hopkins WG, Roberts AD, Pyne DB. Ability of test measures to predict competitive performance in elite swimmers. J Sports Sci, 2008; 26: 123-130

Anderson ME, Hopkins WG, Roberts AD, Pyne DB. Monitoring seasonal and long-term changes in test performance in elite swimmers. Eur J Sport Sci, 2006; 6: 145-154

Atkinson G. Does size matter for sports performance researchers? J Sports Sci, 2003; 21: 73-74

Barbosa TM, Morais J, Marques M, Silva A, Marinho D, Kee Y. Hydrodynamic profile of young swimmers: changes over a competitive season. Scand J Med Sci Sports, 2015; 5: 184-196

Barnes KR, Kilding AE. Running economy: measurement, norms, and determining factors. Sports MedicineOpen, 2015; 1: 1-15

Bishop D, Girard O, Mendez-Villanueva A. Repeated-sprint ability-Part II. Sports Med, 2011; 41: 741-756 
Bishop PA, Jones E, Woods AK. Recovery from training: a brief review. J Strength Cond Res, 2008; 22: 10151024

Bonifazi M, Sardella F, Lupo C. Preparatory versus main competitions: differences in performances, lactate responses and pre-competition plasma cortisol concentrations in elite male swimmers. Eur J Appl Physiol, 2000; 82: 368-373

Bosquet L, Montpetit J, Arvisais D, Mujika I. Effects of tapering on performance: a meta-analysis. Med Sci Sports Exerc, 2007; 39: 1358

Boyd LJ, Ball K, Aughey RJ. The reliability of MinimaxX Accelerometers for measuring physical activity in Australian football. Int J Sports Physiol Perform, 2011; 6: 311-321

Costa M, Bragada JA, Mejias J, Louro H, Marinho D, Silva A, Barbosa TM. Effects of swim training on energetics and performance. Int J Sports Med, 2013; 34: 507-513

Costa MJ, Bragada JA, Mejias JE, Louro H, Marinho DA, Silva AJ, Barbosa TM. Tracking the performance, energetics and biomechanics of international versus national level swimmers during a competitive season. Eur J Appl Physiol, 2012; 112: 811-820

Costill D, Kovaleski J, Porter D, Kirwan J, Fielding R, King D. Energy expenditure during front crawl swimming: predicting success in middle-distance events. Int J Sports Med, 1985; 6: 266-270

Craig $\mathrm{AB}$, Pendergast DR. Relationship of stoke rate, distance per stroke, and velocity in competitive swimming. Med Sci Sports, 1979; 11: 278-283

Deminice R, Gabarra L, Rizzi A, Baldissera V. High intensity interval training series as indices of acidosis tolerance determination in swimming anaerobic performance prediction. Rev Bras Med Esporte, 2007; 13: $185-189$

Fernandes R, Vilas-Boas J. Time to exhaustion at the $\mathrm{VO}_{2 \max }$ velocity in swimming: a review. J Hum Kinet, 2012; 32: 121-134

Fernandes RJ, Sousa M, Pinheiro A, Vilar S, Colaço P, Vilas-Boas JP. Assessment of individual anaerobic threshold and stroking parameters in swimmers aged 10-11 years. Eur J Sport Sci, 2010; 10: 311-317

Figueiredo P, Toussaint HM, Vilas-Boas JP, Fernandes RJ. Relation between efficiency and energy cost with coordination in aquatic locomotion. Eur J Appl Physiol, 2013; 113: 651-659

Hopkins WG. Measures of reliability in sports medicine and science. Sports Med, 2000; 30: 1-15

Hopkins WG. Probabilities of clinical or practical significance, 2002. Available at: sportsci.org/jour/0201/wghprob.htm; accessed on 10.10.2015

Impellizzeri F, Rampinini E, Castagna C, Bishop D, Ferrari Bravo D, Tibaudi A, Wisloff, U. Validity of a repeated-sprint test for football. Int J Sports Med, 2008; 29: 899-905

Lätt E, Jürimäe J, Mäestu J, Purge P, Rämson R, Haljaste K, Keskinen KL, Rodriguez FA, Jürimäe T . Physiological, biomechanical and anthropometrical predictors of sprint swimming performance in adolescent swimmers. J Sports Sci Med, 2010; 9: 398-404

Laursen PB. Training for intense exercise performance: high-intensity or high-volume training? Scand J Med Sci Sports, 2010; 20: 1-10

Liow DK, Hopkins WG. Velocity specificity of weight training for kayak sprint performance. Med Sci Sports Exerc, 2003; 35: 1232-1237

Morais JE, Jesus S, Lopes V, Garrido N, Silva AJ, Marinho DA. Linking selected kinematic, anthropometric and hydrodynamic variables to young swimmer performance. Pediatr Exerc Sci, 2012; 24: 649-664

Morais JE, Marques MC, Marinho DA, Silva AJ, Barbosa TM. Longitudinal modeling in sports: young swimmers' performance and biomechanics profile. Hum Mov Sci, 2014; 37: 111-122

Moreira MF, Morais JE, Marinho DA, Silva AJ, Barbosa TM, Costa MJ. Growth influences biomechanical profile of talented swimmers during the summer break. Sports Biomech, 2014; 13: 62-74 
Mujika I, Chatard J-C, Busso T, Geyssant A, Barale F, Lacoste L. Effects of training on performance in competitive swimming. 1995; 20: 395-406

Mujika I, Padilla S. Detraining: loss of training-induced physiological and performance adaptations. Part I. Sports Med, 2000; 30: 79-87

Neiva H, Fernandes R, Vilas-Boas J. Anaerobic critical velocity in four swimming techniques. Int J Sports Med, 2011; 32: 195-198

Olbrecht J. The science of winning: planning, periodizing and optimizing swim training. Luton: Swimshop; 2000

Pelayo P, Mujika I, Sidney M, Chatard J-C. Blood lactate recovery measurements, training, and performance during a 23-week period of competitive swimming. Eur J Appl Physiol Occup Physiol, 1996; 74: 107113

Pyne DB, Lee H, Swanwick KM. Monitoring the lactate threshold in world-ranked swimmers. Med Sci Sports Exerc, 2001; 33: 291-297

Pyne DB, Mujika I, Reilly T. Peaking for optimal performance: research limitations and future directions. J Sports Sci, 2009; 27: 195-202

Saunders PU, Pyne DB, Telford RD, Hawley JA. Reliability and variability of running economy in elite distance runners. Med Sci Sports Exerc, 2004; 36: 1972-1976

Serpiello FR, McKenna MJ, Stepto NK, Bishop DJ, Aughey RJ. Performance and physiological responses to repeated-sprint exercise: a novel multiple-set approach. Eur J Appl Physiol, 2011; 111: 669-678

Smith DJ, Norris SR, Hogg JM. Performance evaluation of swimmers: scientific tools. Sports Med, 2002; 32: 539-554

Suk M-H, Yu K-H, Shin Y-A. Comparison of tests for measuring maximal exercise ability in elite swimmers. J Exerc Rehabil, 2016; 12: 209-215

Zmijewski P, Cięszczyk P, Ahmetov II, Gronek P, Lulińska-Kuklik E, Dornowski M, Rzeszutko A, Chycki J, Moska W, Sawczuk M. The NOS3 G894T (rs1799983) and-786T/C (rs2070744) polymorphisms are associated with elite swimmer status. Biol Sport, 2018; 35(4): 313-319

\section{Corresponding author:}

\section{Guilherme Tucher}

Universidade Federal do Rio de Janeiro, Escola de Educação Física e Desportos.

Postal address: Av. Carlos Chagas Filho, 540 - Sala A-225 - CEP: 21941-599. Cidade Universitária - Rio de Janeiro, Brazil

Phone: +55 (21) 3938-6809

E-mail: g.tucher@eefd.ufrj.br 